\title{
Effect of Climate Change on the Livelihood of Coastal Areas of Taluka Sonmaini, District Lasbela, Balochistan
}

\author{
${ }^{1}$ Department of Agri. Edu. Ext. \& Short Courses, Sindh Agriculture University, Pakistan \\ ${ }^{2}$ SDSC University of Sindh, Pakistan \\ ${ }^{3}$ Department of Water management, Sindh Agriculture University, Pakistan \\ ${ }^{4}$ Department of Agri. Edu. Ext. \& Short Courses Sindh Agriculture University, Pakistan \\ ${ }^{5}$ Department Energy \& Environment Sindh Agriculture University, Pakistan
}

Muhammad Ismail Kumbhar ${ }^{1}$, Zareen Khan Rind ${ }^{2}$, Faisal Khan Chang*, Nadia Baloch ${ }^{4}$ and Summaya Baloch ${ }^{5}$

Submission: July 15, 2019; Published: August 19, 2019

*Corresponding author: 3Faisal Khan Chang, Department of Water management, Faculty of Agricultural Engineering, Sindh Agriculture University,

Tando jam, Pakistan

\begin{abstract}
The proposed research work was carried out by means of structured survey using a self-report questionnaire and interview schedule containing the main purposes of the present study will be to understand the impacts of climatic variability on livelihood including any slow on-set disaster that experienced by the people of coastal communities in the province of Balochistan. A total of 6 villages were selected as study locations based on the effect of climate variability in the affected areas, 10 respondents from each village was selected making total number of respondents sixty. All the 60 respondents were randomly selected for the research study purpose. Out of the total 70 percent are males and 30 per cent are females. The average ages of the respondents are between 61-38 years. Further it is revealed from the study that the literacy rate is quite low. About 30 percent of the respondents are reported illiterate. The frictional and seasonal unemployment level is high in the study as reported. Nearly 77 per cent male respondents were unemployed from about 3 months to 4 months followed by 23 per cent females. The health condition in the study area reported not satisfactory. Diseases such as Asthma, coronary problems and chronic fever are prevailing among the masses in the study area as reported by the respondents. The survey data exhibit that all respondents are facing food crises and scarcity of clean drinking water. The shortage of effective rainfall aggravated the agricultural sector as major source of crop growing is depending on the regular rainfall. Shortage of rainfall also affected grazing areas as well. Increase in the salinity in the agricultural land also reduced the agricultural products. This scenario shows drought like situation which likely surface food insecurity, malnutrition and ultimately poverty. Nonetheless, the coastal people in the study area, in some cases, are planting trees and developing homestead forest to mitigate the adverse impacts of natural calamities. More than 72 percent household borrow money from neighbors or relatives while about 48 per cent of the household borrow money from mohajan with high interest as data show. Around 20 per cent families are now making mats and other handicrafts to maintain livelihoods More than 68 per cent household are now rearing livestock to meet their basic needs. As reported about 15 percent of the coastal families have cultivated water lemon whereas more than 15 per cent households planted betel leafs to maintain livelihoods.
\end{abstract}

Keywords: Education: Health; Employment; Food insecurity; Clean drinking water and Low rainfall

\section{Introduction}

Agriculture in Pakistan plays major role in economic development. Besides technological advancement, extension plays great role in agricultural development. Farmers generally have no direct linkage with advance agricultural technology hence there is need for massive education and extension efforts to modernize outlook of a common farmer to make him innovative, enterprising and willing to adopt readily to changing situations and technologies. It is the second largest sector, accounting for over 20.9 percent of GDP, and remains the largest employer absorbing 43.5 percent of the country's total labour force. Nearly 69 percent of the country's population resides in rural areas and is directly or indirectly linked with agriculture for their livelihood [1].

Adequate rainfall is the surety of timely water supply for growing healthy crop production and vegetation growth on the grazing pastures. Inversely water shortage leads extreme crop stress and will surface drought like situation as the difference between plant water demand and supply $[2,3]$. 
Being regular exposed to recurring natural hazards, farmers need to adopt their farming systems to differing conditions from year to year. For most, however, agricultural adjustment is a costly option, as investment is needed in re-sowing, crop replacement, intercropping, or irrigation. Increasing climate uncertainties arc an additional threat in disaster prone environmental and one of the major risk factors for risk averseness. Intensity and variability of climatic hazards are expected to steadily increase in the near future due impacts of climate change [4].

There are various types of adaptive responses and coping strategies practiced by the community in the various levels. The empirical findings of the study on adaptive responses of a drought prone area have been gradually outlined. Since drought is the prime fan Hi hazard HI the- study area. The better managerial techniques were found to be the prime factor of people's adaptive management. As the effects of drought overrides across the livelihood groups at various types of all groups are relatively affected by this climatic phenomenon and remain partially impacted due to the various non-climatic and anthropogenic factors [5].

The several adaptive practices or coping measures are regularly considered by the crop producers in the local agriculture but the relative success to overcome climatic condition and temporal variations of climatic elements gradually making people vulnerable. In this situation, the adaptive capacities of the people need to the gradually increased to understand the probabilistic climate vulnerabilities and its consequences over the agriculture and agriculturally based livelihoods [5].

In a study conducted three years ago found that the type of technology and applications through improved technology between the different levels. New crop varieties, new machines, new methods, and unknown risks involved, a complex system, technology transfer is a slow process that requires a long-term commitment, research, education, and adaptation. Technology transfer and adaptation of research results further calculations, for the user, then the wide dissemination of knowledge and investment objectives using different - different categories of farmers, private companies, and so on. There are two parts of the transfer elements, namely, knowledge and commitment [6].

To understand the possible changes in farmers' learning patterns, there is a need to understand what areas of personal and social interactions and situations influence, farmers not only learn about, but also become knowledgeable in newer technologies. While the ideas of upgrading production methodologies is not new, successes have in the past been based on farmer's learning new information from extension group meetings, seminars, or extension publications [7].

Many countries in the world are facing socio-economic crisis because of climate change impacts, considered as one important issue in both national and international level. In 2012 more than 190 countries were gathered in the conference of the parties in Doha to talk and discuss about the essential steps needed to fight against climate change. It has been stated in many reports how climate change is impacting our planet. As the Intergovernmental Panel on Climate Change fourth assessment report mentioned, average temperature of the planet has increased due to anthropogenic greenhouse concentrations in the atmosphere [8].

This has a direct effect on livestock production and livestock systems and as such it is not good for the livelihood of the people especially those residing in the rural areas as it will aggravate their poverty making them more vulnerable to all sorts of external shocks such as diseases and drought. However, the extent of the impact of climate change on livestock production in rural areas has not been ascertained. The study area is mainly affected by drought. Agricultural activities arc largely hampered by different types of climatic hazard. So, adaptation is very much essential for this area for all the sectors of agriculture. Thus, in this situation it is necessary to know the extent of agricultural adaptation, that is why this study was drawn over this [9].

District Lasbela in located in the Province of Balochistan and the Taluka Sonmiani, the study area is situated on the coastal belt of the Lasbela. The Major source of irrigation for crop production is seasonal rainfall. Other irrigation sources are Hab dam, ground water extraction and in some areas karezes are supply water for irrigation and domestic uses. The coastal areas climatic condition is windy and humid while other parts of the district faces hot and dry like climatic environment in summer which last eight months of the year. Accurate data for temperature and precipitation is not available, however, are likely to closely tally to data recorded for Gwadar district.

Lasbela also faces a range of environmental problems due to pollution. Two major sources of pollution of water bodies that is Gadani ship-wreck industry and Gadani Industrial Estate. Gadani is the world's third largest ship breaking yard, consisting of 132 ship-breaking plots located across a 10km long beachfront at Gadani. The Industrial Estate located at Hub is the largest industrial establishment in the Balochistan province that comprises roughly 185 small, medium and large industrial units. The gaseous emission and effluents form both these large industrial establishments have badly affected the local environment and have caused considerably pollution of water bodies and the sea, thus causing damage to fisheries.

\section{Objectives of the Study}

a) To identify the socio-economic status of the respondents living in coastal areas.

b) To explore the climate change related risks (possible impacts) of poor people living in coastal areas.

c) To identify the alternative livelihood adaptation strategies of people to climate change. 
d) To suggest recommendation for climate change adaptation for the livelihood of coastal areas.

\section{Materials and Methods}

The proposed research work was carried out by means of structured survey using a self-report questionnaire and interview schedule containing the main purposes of the study will be to understand the impacts of climatic variability on livelihood including any slow on-set disaster that experienced by the people of coastal communities in Balochistan. Show in Figure 1.

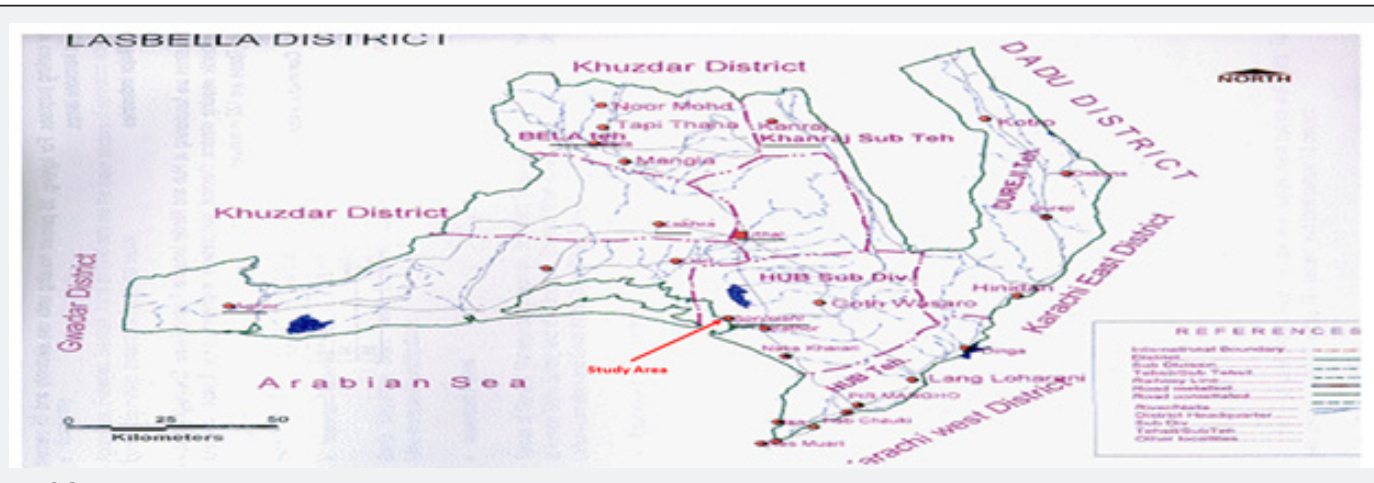

Figure 1: Map of Study Area.

\section{Research design}

Selection of the region is an important step in any study. Such research is usually required to set the selection area for the study according to the determined target data. For the present study, six villages of tehsil SONMAINI, district Lasbella were purposively selected, because farmers of those area grow more agriculture in their homestead.

\section{Selection of sample}

The present study was followed a triangulation method i.e., a combination of quantitative and qualitative research methods. This study was carried out by survey method. The data was collected by taking interviews using a well-structured questionnaire. A total of 6 villages were selected as study locations based on the effect of climate variability in the affected areas, 10 respondents from each village was selected. The total number of 60 farmers were randomly selected for the study from the study area.

\section{Data collection}

Well-structured questionnaire design, and data collection and research to limit the list of mentors to help growers faced under development. Questionnaire consisting of three parts (A. General Information B. perceive the overall analysis, C. comments). Respondents were willing to provide the information needed for the research purposes. Most of the respondent interviewed in their respective fields. Researchers interviewed them in the morning time, when they are working in the field.

\section{Data analysis}

The initial data is arranged in the coding system and the organization. After using the coding table, collected the encoded data, all the data tables, aggregated, and analyzed by SPSS (Statistical Package for Social Sciences) computer software.
Frequency, mean, standard division and Level SPSS (PC) program calculates.

\section{Results}

This part presents the findings of the study. The present section has furnished the information on the social, economic and demographic characteristics of sample households of the study.

\section{Socio-economic profile of the respondents}

The present section has furnished the information on the social, economic and demographic characteristics of sample households of the study.

(Figure 2) The study consists of 60 respondents of which 70 percent are males and 30 per cent are females.

\section{Gender category of respondents}

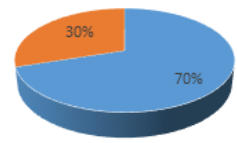

Figure 2: Gender category of respondents.

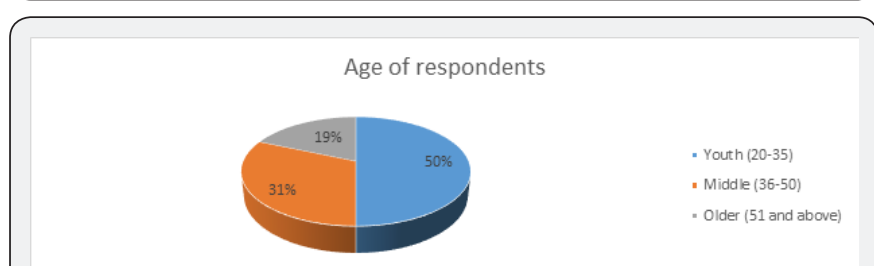

Figure 3: Age of respondents.

(Figure 3) The average age of the youth group respondents were around 45 years while average of middle age group were 
about 28 years and older age respondents average age were 17 years.

(Figure 4) The above paragraph shows a substantial variation in the educational attainment of the respondents. It is revealed that a small number of respondents were able achieve high level of education. The data shows that only 4 percent respondents achieved graduate and post graduate degrees which show high level of dropouts. The Primary level education which is five years basic education attended by about 37 percentage of the respondents followed by15 percent up to class eight, 12 percent up to Matric and about only 3 percent of respondents completed intermediate degree. Due to lack of available support from family they were unable to continue their higher study. Another significant finding is that more than 30 per cent of the respondents were illiterate.

\section{Education level of respondents}

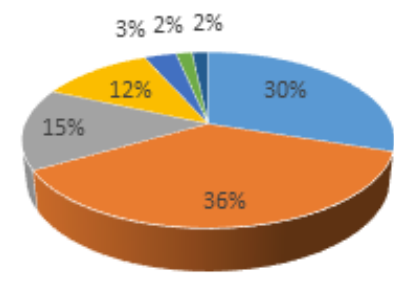

$$
\begin{aligned}
& \text { - Iliterate } \\
& \text { - Primary } \\
& \text { - Middle } \\
& \text { - Matric } \\
& \text { - Inter mediate } \\
& \text { - Graduation }
\end{aligned}
$$

Figure 4: Education level of respondents.

\section{Impact of climate change on Employment, Income and occupation}

(Figure 5) The data further shows that out of 60 respondents nearly 77 percent males were unemployed from about 3 months to 4 months followed by 23 percent females. Besides, among 72 percent male respondents mentioned that they remained unemployed for about 5-6 months and 28 percent males' respondents remained unemployed for about 11-12 months. On the other hand, about 33 percent female respondents remained unemployed from about 1 month to 2 months and remaining 67 percent females have no job up to 10 months. It is evident that irrespective of gender variation, a significant number of males and females are unemployed in the coastal zone. It suggests that there is frictional and seasonal unemployment issue.

\section{IMPACT OF CLIMATE CHANGE ON THE UNEMPLOYMENT OF THE RESPONDENTS}

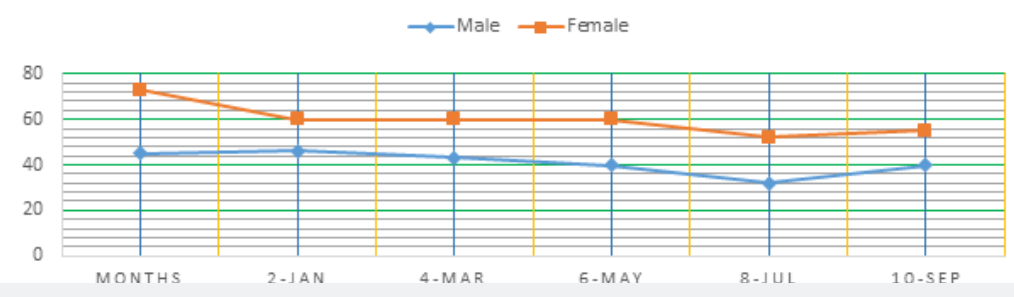

Figure 5: Impact of climate change on the unemployment of the respondents.

(Figure 6) The respondents who were suffering from asthma or breathing trouble among them about 5 percent are females while around 28 percent are males. Besides, 28 percent of the females and 12 percent of male respondents reported that they were suffering from high blood pressure. It is also found that 13 percent male respondents suffered from chronic fever and about 7 percent from Coronary disease, while 5 percent of females suffering from chronic fever. The findings also show that it is the female respondents who suffer more $(28.33 \%)$ compared to male respondents (11.67\%) from high blood pressure. Moreover, the respondents shared that there is prevalence of some other diseases like arthritis/rheumatism (5.2\%) and eczema (10\%).
The Figure 7 shows the risks created by climate change in all areas. The survey data exhibit that all respondents are facing food crises and scarcity of pure drinking water. Food is now seen as an acute problem in the climate change affected areas while the coastal people are unable to find due to scarcity of clean drinking water. On the other hand, soil salinity and waterlogging are also main problem which negatively effecting the productivity of the land. The main cause of land degradation is rise of sea level as narrated by the respondents of the coastal Lasbela. Soil Salinity has devastated the cultured fisheries and the back-yard gardens, and it decreased the crop production resulting food insecurity, malnutrition and poverty among the masses in the study area, as reported. 


\section{International Journal of Environmental Sciences \& Natural Resources}

Chromic illness of the respondents due to climate change

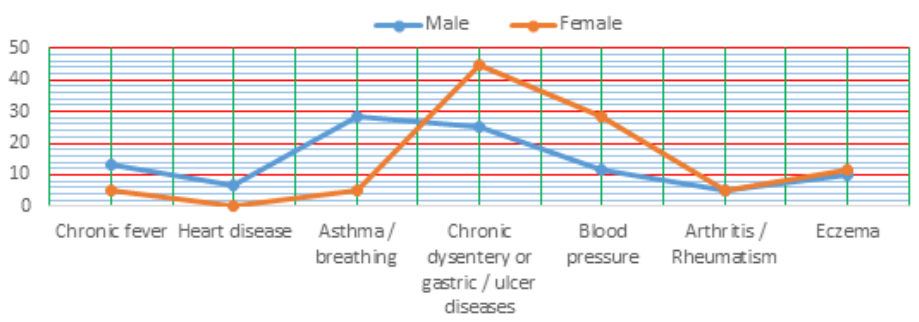

Figure 6: Chromic illness of the respondents due to climate change.

Types of risks faced by the coastal community due to disasters

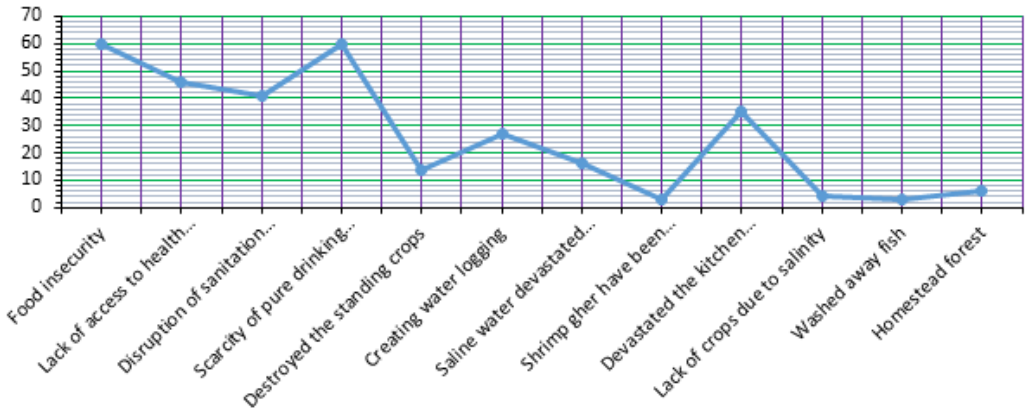

Figure 7: Types of risks faced by the coastal community due to disasters $=60$.

Conspicuously, it is positive venture that coastal people, in some cases, are planting trees and developing homestead forest to mitigate the adverse impacts of natural calamities. Disasters like cyclones and floods have destroyed and have washed away fish from the ponds. Because of these losses, the coastal people are also unable to afford the health care services. So, it is clear that the people who are encountered with climate change are more prone to climatic risks.

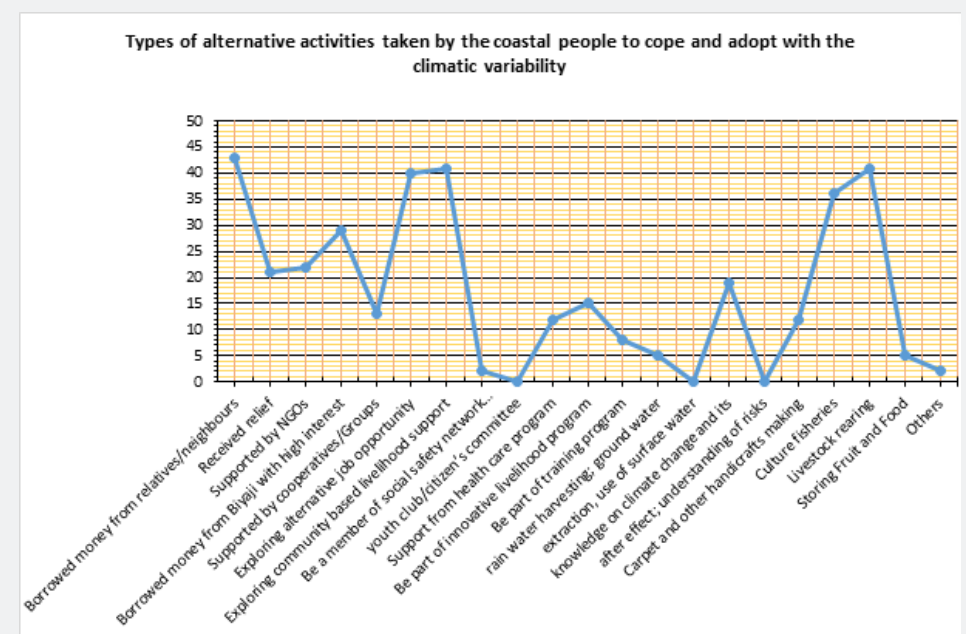

Figure 8: Types of alternative activities taken by the coastal people to cope and adopt with the climatic variability.

\section{Alternative activities taken by climate change affected} people

The following Figure 8 presents that to solve the food crisis or other problems about 72 percent households borrow money from neighbors or relatives while more than 48 percent of the households borrow money from Biyaji with high interest. Around 20 per cent families are now making carpets and other handicrafts to maintain livelihoods. Livestock rearing is also an important source of income in the rural area of the country and it apparently seen here as well. Though, the affected people cannot 
rear poultry and layer due to lack of dry space but have taken livestock rearing as a main income earning source. For example, more than 68 percent households are now rearing livestock to meet their basic needs. Besides, livestock rearing, and sweet water fish cultivation are also found as important sources of income of 60 percent households. As, frequent cyclones destroyed houses of coastal people, they have to take shelter at the school compounds. At this time, schools are kept closed as they are used as cyclone shelters or temporary residence for the homeless people. The affected people are also getting assistances from NGOs or other cooperative groups. These NGOs and cooperatives involved affected people in communitybased livelihood programs and providing training in different livelihood activities.

Many people are becoming members of social safety network programs supported by youth club/citizens committee and participating innovative livelihood programs initiated by government or other organizations. Besides these alternative strategies, the affected people are also trying to increase their knowledge on climate change, its' after effects and associated risks. They think that the knowledge on climate change and understanding of risk-averse would help to learn more on crop cultivation patterns. Different clubs and citizen committees have been formed by GOs and NGOs to make people knowledgeable on the effects of climate change became more resilient. Water for domestic purposes and crop production is also another acute problem in the study area. The local people have also developed a system with the help of NGOs and GOs to store rain water as well as extract underground water with use of tube wells. Moreover, affected people are also preserve rain water. During monsoon period they store drinking water into water filters placing them on house roofs. They are also using surface water and extracting ground water for agricultural cultivation and other household tasks. However, they are becoming more resilient by adopting different types of strategies to strive with the climate change.

\section{Discussion}

Farmers use modern technologies when they find those useful in their own socio-economic set-up and agro-economic settings. Moreover, the impact of information and communication technologies differ from farmer to farmer that is, farmer's individual characteristics and personal make-up play a vital role in adopting any agricultural practice in the overall technology transfer process. A particular technology might be proved beneficial or suitable for a farmer, but he may not be in a position to accept it due to his varied mental make-up and situational factors. The individual characteristics of the farmers may greatly vary and the various factors might have great impact on their use of various information and communication technologies.

The overall proportion of the younger age groups is substantially larger than that of older age groups for each sex. The present study shows a substantial variation in the educational attainment of the respondents. It is revealed from the study that a very insignificant number of the respondents (4\%) have obtained master's degree and graduation degrees. On the other hand, about 36 per cent respondents have completed primary level education followed by 15 percent up to class eight, 12 percent achieved ten years of study that is matric level (S.S.C) and around 3 percent of respondents got education up to intermediate level (H.S.C). Due to lack of available support from family they were unable to continue their higher study. Another significant finding is that more than 30 percent of the respondents never attended any school/madrasa/formal educational institute.

Income distribution has been categorized into landless laborer, vulnerable and destitute, marginal farmers, small farmers, medium farmers and larger farmers. Women are generally more vulnerable than men to climate-related impacts due to their social status, cultural norms, lack of access to and control over resources, and lack of participation in decisionmaking processes in the developing countries [10].

The research study reveals that out of 60 respondents nearly 77 percent males were unemployed from about 3 months to 4 months followed by 23 per cent females. Besides, among 72 percent male respondents mentioned that they remained unemployed for about 5-6 months and 23 percent males' respondents remained unemployed for about 11-12 months. On the other hand, about 33 per cent female respondents remained unemployed from about 1 month to 2 months and remaining 67 percent females have no job up to 10 months. It is evident that irrespective of gender variation, a significant number of males and females are unemployed in the coastal zone. In recent studies Nasreen [11] shows that climate change induced disasters affect both women and men but the burden of coping with disasters falls heavily on women. Since, additional works are also performed by women to deal with the adverse situation. According to same study, it further mention that during and aftermath of a disaster men in rural areas lose their places of work while women shoulder the responsibilities to maintain households' sustenance.

The respondents were suffering from asthma or breathing problems among them about 5 percent are females while around 28 per cent are males. Besides about 28 percent of the female's respondents reported that they suffer from high blood pressure, compare about 12 percent are males. It is also found that more than 13 percent male respondents suffered from chronic fever and about 7 percent from heart disease, while 5 percent of females were suffering from chronic fever. Moreover, the respondents shared that there is prevalence of some other diseases like arthritis/rheumatism (5.2\%) and eczema (10\%). The household assets including human health and motivation, houses, trees, other physical assets, livelihood tools and equipment's are destroyed in the extreme weather events and thus reducing capitals to pursue livelihoods and accordingly reducing resilience to extreme conditions. 
The findings show the risks created by climate change in all areas. The survey data exhibit that all respondents are facing food crises and scarcity of clean drinking water. Food is now seen as an acute problem in the climate change affected areas while the coastal people are unable to find due to scarcity of clean/ hygienic drinking water. The degradation of soil due to salinity and waterlogging as reported another alarming situation in the study area, which drastically decreased the productivity of the land and at the same time destroyed backyard homesteads in research area. Consequently, it adversely affected the incomes of the people and resulting more poverty.

The coastal people, in some cases, are planting trees and developing homestead forest to mitigate the adverse impacts of natural calamities. Disasters like cyclones and floods have destroyed and have washed away fish from the pond. Like floods and cyclone, tidal surge inundated and washed away shrimp ghers. Because of these losses, the coastal people are also unable to afford the health care services. So, it is clear that the people who are encountered with climate change are more prone to climatic risks. Researchers pointed out that agriculture in Bangladesh "is already under pressure from increasing demands for food and the parallel problems of depletion of agricultural land and water resources from overuse and contamination. Climate variability and projected global climate change makes the issue particularly urgent [12].

The present results show that that to solve the food crisis or other problems more than 72 percent household borrow money from neighbors or relatives while more than 48 percent of the household borrow money from mohajan with high interest. During a particular time, they are taking this mean, but the means of borrowing money is not a last long solution. Though, they got relief from the government and NGOs, it increases the burden of loan. As a result, in disasters prone areas the coastal communities are trying to solve their problems by selling mat and other handicrafts in the local markets. Around 20 per cent families are now making mats and other handicrafts to maintain livelihoods. Livestock rearing is also an important source of income in all over the country. Though, the affected people cannot rear poultry and layer due to lack of dry space but have taken livestock rearing as a main income earning source. For example, more than 68 percent household are now rearing livestock to meet their basic needs. Besides, livestock rearing, and sweet water fish cultivation are also found as important sources of income of 60 percent households.

During flood, food availability is found as major problem. Women store food and fruits to solve the problem of food for rainy days. Women face problems in cooking due to lack of water and wood for fuel. Agricultural lands are gradually losing its topsoil fertility. Agricultural crops and vegetables cannot grow due to saline water and extreme temperature. The coastal people are now trying to cultivate extreme weather suitable and salinity tolerant crops. For example, 15 per cent of the coastal families have cultivated water lemon whereas more than 15 per cent households planted betel leafs to maintain livelihoods.

As, frequent cyclones destroy houses of coastal people, they have to take shelter at the school compounds. At this time, schools are kept closed for education as they are used as cyclone shelters or temporary residence for the homeless people. However, they face difficulties at cyclone shelter as they are not sufficient. The affected people are also getting assistances from NGOs or other cooperative groups. These NGOs and cooperatives involved affected people in community-based livelihood programs and providing training in different livelihood activities. Many people are becoming members of social safety network programs supported by youth club/citizens committee and participating innovative livelihood programs initiated by government or other organizations.

Besides these alternative strategies, the affected people are also trying to increase their knowledge on climate change, its' after effects and associated risks. They think that the knowledge on climate change and understanding of risks would help to learn more on crop cultivation patterns. Different clubs and citizen committees have been formed by GOs and NGOs to make people knowledgeable on the effects of climate change become more resilient. Water is also another acute problem in the study area. The local people have also developed a system with the help of NGOs and GOs to store rain water as well as ground water. Moreover, affected people are also harvesting rain water. During monsoon period they store drinking water into water filters placing them on house roofs. They are also using surface water and extracting ground water for agricultural cultivation and other household tasks. However, they are becoming more resilient by adopting different types of strategies to strive with the climate change $[13,14]$.

\section{Conclusion}

The study consists of randomly selected 60 respondents of which 70 percent are males and 30 per cent are females. Furthermore, all respondents stratified into age groups; Youth between 20-35 years; middle between 36-50 year and older above 15 years. The educational level of the respondents observed not satisfied. The graduate and postgraduate levels were found only 4 percentage altogether, while intermediate levels were about 3 percentage of the total. The Matric levels or till ten-year education were 12 percentages. The primary education that is 5 -year completion of the education were 36 percentage. The high dropout from the schools and college side reported were not affordability of parents for further study of the children.

The health points of view the people of study area were suffering different types of diseases, such as asthma, high blood pressure, coronary issue and chorionic fever. The basic health facilities were not satisfactory in the research area. 
The unemployment level in the area looming high, nonetheless, all unemployed are seemed either due to seasonal factor or frictional unemployment. Because majority of the respondents were unemployed not more 6 months, only few reported that they couldn't get any job for 10-12 months. As reported food insecurity prevails in the region due to the water shortage and degradation of the land. The availability of clean and hygienic water is another problem in the research area. To cop this situation people with the help of GO's and NGO's developed better techniques to store the rain water and extract the ground water for domestic use and crop production particularly vegetables in the backyard.

Furthermore, in time of the urgency they borrow money from different informal financial sources which charge them high interest rates such as Mahajans, the local merchants. However, they also borrow money from neighbors and relatives with no interest. Like other parts of country these people also rear livestock for diary product and commercial purpose to sustain livelihood. Apart, it seems good gesture that in some cases people plant trees for shade, commercial purpose and environment (beautify) point of view. The farming watermelon, weaving mats for sale, planting betel for leaf is another sources of the income of the people in the study area. Betel wine growing is intensive capital and labor activity which rich farmers can afford it.

\section{Suggestions}

a) It is evident from the study that in order to cope and/or adapt with the unexpected conditions contributed by climate change local communities are taking multiple alternative livelihood strategies based on their indigenous knowledge and coping mechanisms.

b) They are trying to adopt with the adverse impacts of climate change by adopting alternative livelihood options such as rearing poultry, planting trees, cultivating vegetables in homestead land, using pond sand filter and harvesting rain water etc. to enhance their livelihood capacities.

c) The government and other bodies are also providing supports to local people to develop a resilient society through their adaptation strategies.

d) The government, often with support from development partners, INGOs, NGOs has introduced social safety net programs and alternative employment opportunities for the disaster affected coastal people which need to be enhanced at large scale.

e) Some of these include capacity building training in cottage industry, providing salinity tolerant seed and try to minimize their risks by strengthening capacity and building their assets.

f) However, the initiatives are not sufficient to overcome the challenges of coastal people. By examining various impacts of climate change, the present study has given importance on the interlinkages amongst different governmental and non-governmental organizations and local communities.

g) The study also draws an attention to the institutional and economic factors and opportunities that facilitate people's well beings to cope with climate variability and climate induced disasters.

\section{References}

1. GoP (2015) Economic Survey of Pakistan. Economic Advisor's Wing, Finance Division, Islamabad, Pakistan.

2. Venkateswarlu J (1997) Sustainable Crop Production. In: Symposium on Recent Advances in Management of Arid Ecosystems. Arid Zone Research Association of India, Jodhpur, India.

3. Kulik MS (1958) Agroclimate indices of Drought. In: Davidaya FF, Kulik MS (Eds.), Hydrometerological Publishing, Moscow, trans. A. Nurlik, Meteorological Translation 7: 75-81.

4. Ahmed AU, Alam M, Rahman AA (1994) Adaptation to Climate Change in Bangladesh: Future outlook. In: Huq S, Karim RZ. Miah T (Eds.), Vulnerability and Adaptation to Climate Change for Bangladesh. Boston, London: Academic Publishers, pp. 67-83.

5. CEGIS (2005) Final Report of study on Livelihood systems assessments, vulnerable groups profiling and livelihood adaptation to climate hazard and long-term climate change in drought prone areas of Under Support to the strengthening of CDMP Project. Dhaka, Bangladesh.

6. Sivanarayan G, Jayarama Reddy (2005) Constraints in the adoption of improved sheep and goat practices by the small and the marginal farmers of diversified farming. Indian J Dairy Sci 48(4) :306-308.

7. McCown RL (2002) Changing systems for supporting farmers' decisions: problems, paradigms, and prospects. Agricultural Systems 74(1): 179-220.

8. IPCC (2007) Contribution of Working Group II to the Fourth Assessment Report of IPCC on Climate Change, 2007. Impacts, Adaptations and Vulnerability. Cambridge, United Kingdom and New York, USA, p. 327.

9. Majahodvwa SN, Masuku MB, Manyatsi AM (2014) The Impact of Climate Change on Livestock Production in Swaziland: The case of Mpolonjeni Area Development Programme. Journal of Agricultural Studies 2(1): 1-15.

10. Khan, Iqbal Alam (2010) The Social Dimensions of Adaptation to Climate Change in Bangladesh The International Bank for Reconstruction and Development, The World Bank.

11. Nasreen, Mahbuba. (2012) Women and Girls Vulnerable or Resilient? Institute of Disaster Management and Vulnerability Studies, University of Dhaka, Dhaka-1000.

12. Selvaraju R (2006) Livelihood Adaptation to Climate Variability and Change in Drought Prone Areas of Bangladesh, ADPC, FAO. World Bank (2006) Bangladesh Country Environmental Analysis. Bangladesh Development Series Paper No: 12 The World Bank Office, Dhaka.

13. Nasreen M (2008) Impact of Climate Change on Food Security in Bangladesh: Gender and Disaster Perspectives. paper presented at the International Symposium on Climate Change and Food Security in South Asia, Dhaka, pp. 25-30.

14. OXFAM (2009) Disaster Risk Reduction, Climate change and livelihood of the poor and marginalized people. A Framework for Oxfam GB Bangladesh. 
DOI: 10.19080/IJESNR.2019.21.556053

Your next submission with Juniper Publishers will reach you the below assets

- Quality Editorial service

- Swift Peer Review

- Reprints availability

- E-prints Service

- Manuscript Podcast for convenient understanding

- Global attainment for your research

- Manuscript accessibility in different formats (Pdf, E-pub, Full Text, Audio)

- Unceasing customer service

Track the below URL for one-step submission https://juniperpublishers.com/online-submission.php 